\title{
Thermal Load Considerations for Detonative Combustion-Based Gas Turbine Engines
}

Daniel E. Paxson and H. Douglas Perkins

Glenn Research Center, Cleveland, Ohio 
Since its founding, NASA has been dedicated to the advancement of aeronautics and space science. The NASA Scientific and Technical Information (STI) Program Office plays a key part in helping NASA maintain this important role.

The NASA STI Program Office is operated by Langley Research Center, the Lead Center for NASA's scientific and technical information. The NASA STI Program Office provides access to the NASA STI Database, the largest collection of aeronautical and space science STI in the world. The Program Office is also NASA's institutional mechanism for disseminating the results of its research and development activities. These results are published by NASA in the NASA STI Report Series, which includes the following report types:

- $\quad$ TECHNICAL PUBLICATION. Reports of completed research or a major significant phase of research that present the results of NASA programs and include extensive data or theoretical analysis. Includes compilations of significant scientific and technical data and information deemed to be of continuing reference value. NASA's counterpart of peerreviewed formal professional papers but has less stringent limitations on manuscript length and extent of graphic presentations.

- TECHNICAL MEMORANDUM. Scientific and technical findings that are preliminary or of specialized interest, e.g., quick release reports, working papers, and bibliographies that contain minimal annotation. Does not contain extensive analysis.

- CONTRACTOR REPORT. Scientific and technical findings by NASA-sponsored contractors and grantees.
- CONFERENCE PUBLICATION. Collected papers from scientific and technical conferences, symposia, seminars, or other meetings sponsored or cosponsored by NASA.

- SPECIAL PUBLICATION. Scientific, technical, or historical information from NASA programs, projects, and missions, often concerned with subjects having substantial public interest.

- TECHNICAL TRANSLATION. Englishlanguage translations of foreign scientific and technical material pertinent to NASA's mission.

Specialized services that complement the STI Program Office's diverse offerings include creating custom thesauri, building customized databases, organizing and publishing research results ... even providing videos.

For more information about the NASA STI Program Office, see the following:

- Access the NASA STI Program Home Page at http://www.sti.nasa.gov

- E-mail your question via the Internet to help@sti.nasa.gov

- Fax your question to the NASA Access Help Desk at 301-621-0134

- Telephone the NASA Access Help Desk at 301-621-0390

- Write to:

NASA Access Help Desk

NASA Center for AeroSpace Information 7121 Standard Drive

Hanover, MD 21076 
NASA/TM-2004-213190

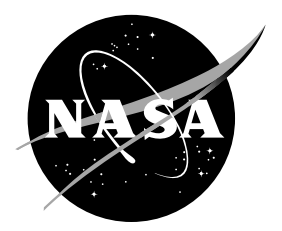

\section{Thermal Load Considerations for Detonative Combustion-Based Gas Turbine Engines}

Daniel E. Paxson and H. Douglas Perkins

Glenn Research Center, Cleveland, Ohio

Prepared for the

40th Joint Propulsion Conference and Exhibit

cosponsored by AIAA, ASME, SAE, and ASEE

Fort Lauderdale, Florida, July 11-14, 2004

National Aeronautics and

Space Administration

Glenn Research Center 
This report is a formal draft or working paper, intended to solicit comments and ideas from a technical peer group.

This report contains preliminary findings, subject to revision as analysis proceeds.

Trade names or manufacturers' names are used in this report for identification only. This usage does not constitute an official endorsement, either expressed or implied, by the National Aeronautics and Space Administration.

This work was sponsored by the Low Emissions Alternative Power Project of the Vehicle Systems Program at the NASA Glenn Research Center.

Available from

NASA Center for Aerospace Information 7121 Standard Drive

Hanover, MD 21076
National Technical Information Service 5285 Port Royal Road Springfield, VA 22100 


\title{
Thermal Load Considerations for Detonative Combustion-Based Gas Turbine Engines
}

\author{
Daniel E. Paxson and H. Douglas Perkins \\ National Aeronautics and Space Administration \\ Glenn Research Center \\ Cleveland, Ohio 44135
}

\begin{abstract}
An analysis was conducted to assess methods for, and performance implications of, cooling the passages (tubes) of a pulse detonation-based combustor conceptually installed in the core of a gas turbine engine typical of regional aircraft. Temperature-limited material stress criteria were developed from common-sense engineering practice, and available material properties. Validated, one-dimensional, numerical simulations were then used to explore a variety of cooling methods and establish whether or not they met the established criteria. Simulation output data from successful schemes were averaged and used in a cycle-deck engine simulation in order to assess the impact of the cooling method on overall performance. Results were compared to both a baseline engine equipped with a constantpressure combustor and to one equipped with an idealized detonative combustor. Major findings indicate that thermal loads in these devices are large, but potentially manageable. However, the impact on performance can be substantial. Nearly one half of the ideally possible specific fuel consumption (SFC) reduction is lost due to cooling of the tubes. Details of the analysis are described, limitations are presented, and implications are discussed.
\end{abstract}

\section{Introduction}

$\mathrm{P}$ ulse Detonation Engine (PDE) technology is currently under investigation for potential application in systems where the detonative device is coupled to conventional turbomachinery. Such systems are sometimes referred to as Hybrid PDE's. One such system envisions the detonative device to be in the position normally occupied by the conventional, steady, constant pressure combustor. This arrangement creates what may be thought of as a detonative pressure-gain combustor (DPGC). From a thermodynamic standpoint a gain in total pressure (rather than the normal loss or idealized constant pressure typical of conventional combustors), at the point in the cycle where the heat is added leads to increased efficiency, increased specific thrust, and reduced specific fuel consumption (SFC). Although turbofan-type engines are the target for such systems, an idealized examination of a turbojet application ${ }^{1}$ can give some idea of the potential benefit. Figure 1 shows the SFC for idealized constant-pressure combustor, and DPGC topped turbojet engines as a function of mechanical Overall Pressure Ratio (OPR). Sea-Level static flight conditions are assumed. The ratio of specific heats is 1.3. The turbine inlet temperature is $2968 \mathrm{R}$. The fuel heating value is $19,800 \mathrm{BTU} / \mathrm{lbm}$. Two detonative results are shown: those derived from an idealized, thermodynamic cyclebased analysis ${ }^{2}$ and those obtained from a curve-fit to the mass-averaged output of an idealized, unsteady onedimensional, computational model. ${ }^{3}$

For topping cycle analyses using a calorically perfect gas, these results are most easily utilized in the form of total pressure ratio across the device plotted against total temperature ratio across the device, as shown in fig. 2 . The data derived from ref. 2 may be plotted as a single curve, as shown in red. The ref. 3 data consists of multiple curves, each representing a different fueling stoichiometry. Two such curves are shown using blue and blacksymbols. The green line, identified in fig. 2 as the ref. 3 fit (and used to obtain fig. 1), passes through the peak values of the multi-parameter ref. 3 data at a given temperature ratio.

Figure 1 also shows the percent reduction in SFC due to the ref. 2 detonative pressure-gain calculations compared to constant pressure combustion. Reductions such as these (5 to 12 percent) could represent substantial savings in fuel-burn, which may, in-turn lead to large emissions reductions in future commercial engines.

Though the performance enhancement potential of detonation-based combustors is impressive, many issues stand between concept and implementation, and all of these must be addressed. The issues are both theoretical, and practical. Theoretically for example, there is still disagreement as to the performance enhancing potential of detonative combustion. ${ }^{4}$ 


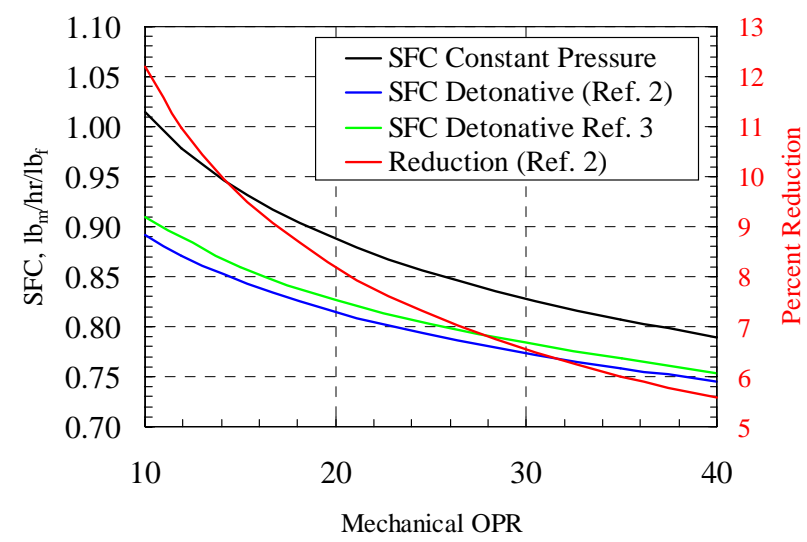

Figure 1.-Idealized specific fuel consumption for constantpressure, and detonative combustion-topped turbojet engines as a function of mechanical overall pressure ratio. Detonative calculations are based on the work of refs. 2 and 3. SeaLevel static flight conditions are assumed. The ratio of specific heats is 1.3 . The turbine inlet temperature is $2968 \mathrm{R}$.

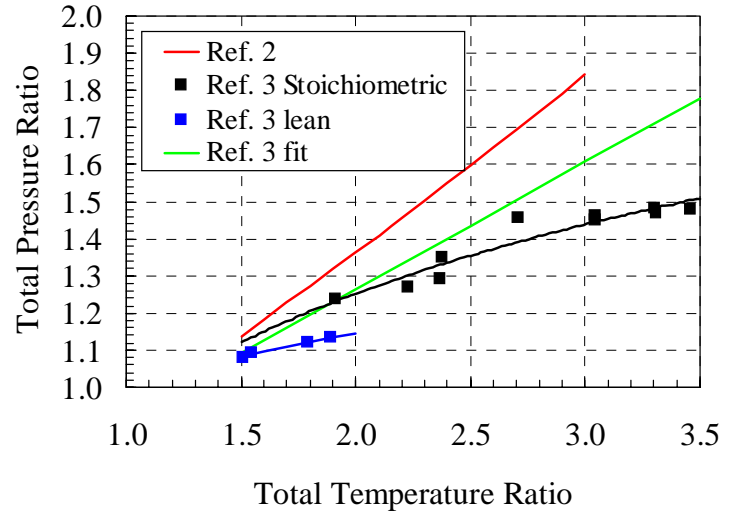

Figure 2.-Idealized total pressure ratio vs. total temperature ratio across a detonative pressure-gain combustor. Results derived from ref. 2 and computed from ref. 3 are shown.

Practically, the list of issues is dauntingly long, and complicated by the fact that many are coupled (i.e., addressing one impacts another). Ducting, valving, detonation of liquid fuels, auto-ignition, turbomachinery cooling flows, unsteady turbomachinery interactions, fatigue, noise, and thermal management, to name a few, must all be assessed and tackled in order for detonative pressure-gain combustion to be viable. In this paper, an initial step is made at assessing just one of those issues, namely cooling or thermal management of the detonative component. The rational for assessing this particular issue is as follows. Thermodynamically the same effect as a pressure-gain combustor could be achieved by simply adding another turbomachinery spool containing a compressor, combustor (of the conventional type), and turbine. Realistically however, thermal loading of such a device would exceed current material limits. If detonative pressure-gain combustion is to be viable therefore, it must be shown that, in implementation, it does not face the same excessive thermal loading.

Most detonative combustors are envisioned as a series of tubes that either spin in order to affect valving, or are fixed and have some sort of rotary valve mechanism at the inlet, and possibly exhaust ends. The overall massaveraged enthalpy ratio of the device is established by the allowable turbine inlet temperature and the prescribed compressor discharge temperature (essentially dictated by engine OPR and flight conditions). In nearly all modern engines under consideration for use with a detonative combustor, this allowable enthalpy ratio is far below what would result if the detonative device were to operate with fully fueled, fully purged stoichiometric detonation.

It is tempting to bypass this limitation by considering detonative combustors that replace stages of conventional compression with the pressure rise that they provide. This would allow for potentially larger enthalpy ratios. Examination of fig. 1 however, demonstrates that this is not practical for more than a stage or two. Using the results of ref. 3, it can be seen that a conventional Brayton cycle with a 30:1 mechanical OPR has approximately the same SFC as a detonation topped 20:1 mechanical OPR cycle. With a typical compression stage having a pressure ratio of 1.3 , this means that equivalent (not superior) performance can be obtained by removing 1.5 stages. Removal of more than this results in a less efficient, higher SFC machine. Thus, substantial performance enhancement is only possible by detonatively topping an existing gas turbine, not by replacing components. ${ }^{5-7}$

With this restriction then, only relatively small enthalpy ratios are possible. Hence, some means must be provided to create, from the vantage point of the turbine, very lean combustion. It is possible that actual lean detonation can be achieved in this environment; however it is more likely that the lean exhaust temperature will be achieved through a large amount of bypass flow (flow not passing through the detonative device), a substantial amount of under- or partial-fueling of the tubes, or substantial over-purging (with unfueled air). Each of these methods carries with it a different performance cost; however, each also presents a different thermal load to, and cooling capacity for, the tubes of the detonative device. As in conventional turbomachinery, accommodation of 
thermal loading carries with it another set of losses that must be assessed in order to obtain realistic potential performance for a given implementation of detonative combustion.

This paper will focus on the trade-off between these performance costs and capacities for a particular gas-turbine engine topping application. Primary consideration will be given to operational modes in which the detonation tubes are fixed (e.g., with rotary valves); however, the wave rotor, or spinning tube mode will be briefly considered. Straight tubes of constant cross sectional area will be assumed. There is conceptual evidence that area variation may enhance performance, ${ }^{8}$ and that curved, spinning tubes from which shaft work is extracted can be beneficial. ${ }^{9}$ However, both of these modifications are beyond the scope of the present, preliminary study. Cooling of the tubes, both internally and externally is considered to be purely convective via the working fluid. The impact of Thermal Barrier Coatings will not be considered except to point out those cases where they would be ineffective. For the stationary tube configurations, it will be assumed that the exit static pressure matches the inlet total pressure. For the wave rotor based configurations, the exit static pressure is slightly less. The rational for these choices may be found in refs. 3 and 10.

The bulk of the analysis is carried out using a quasi-one-dimensional, time-accurate CFD code which has relevant loss models added for viscous effects and heat transfer. ${ }^{3,10,11}$ The ability of this code to predict the performance of detonative devices with reasonable accuracy has been documented in ref. 3. Details of the code have been documented in the literature and, as such will not be described here. However, the accuracy of the heat transfer model, a critical element to the present study, will be discussed in the next section. Additional loss sources such as valving, and initiation devices can be modeled with the code, but have not been utilized in the present study. Thus, the code results represent idealized performance save for the particular phenomenon of interest.

Four implementation methods for achieving the prescribed mass-averaged total temperature ratio, and sufficient cooling will be considered:

I. Lean, fully filled, fully fueled detonation, without bypass flow.

II. Stoichiometric, fully filled, partially fueled detonation, without bypass flow.

III. Stoichiometric, fully fueled detonation, with over-purging, without bypass flow.

IV. Stoichiometric, fully fueled detonation with bypass flow, and subsequent mixing.

In each case the tubes will be sized according to the through-flow requirements and compatibility considerations with the surrounding turbomachinery. For example, the mean diameter of a tube cluster should closely match the exit diameter of the high pressure compressor. Furthermore, the length of the device (not including estimates of ducting requirements) should not significantly lengthen the engine.

The candidate engine into which the combustor implementation methods will conceptually fit will be described in a separate section. A brief rationale regarding the selection of this particular engine will also be included.

Allowable tube wall temperature limits will be based on published superalloy material properties at elevated temperatures, and estimated high-cycle fatigue stresses induced by the repetitive detonative process. A method for calculating these limits will be described.

Overall performance of the system (detonative combustor with associated turbomachinery) will be presented in the form of engine specific fuel consumption and will be compared to a baseline conventional combustion (constant static pressure) engine of the same mechanical OPR. This will be accomplished by first calculating the performance of the numerically simulated detonative combustor using the mixing method described in ref. 3 . This method computes an average overall total pressure ratio from the integrated exhaust momentum of the combustor tubes and the prescribed inlet total pressure. The combustor temperature ratio is, as mentioned, prescribed. These two quantities, pressure ratio and temperature ratio are then used in a validated, non-ideal, component level cycle deck to calculate system performance. The cycle deck is briefly described in Appendix 1 of this paper.

It will be shown that the thermal loading is very high in these devices, and represents a substantial challenge to their practical application. In particular, two of the implementation methods listed cannot provide sufficient cooling and one of the methods that does provide adequate thermal management (Method IV) suffers a substantial performance penalty. However, there are implementation methods which meet the preliminary thermal management requirements developed, and still show substantial performance enhancement. 


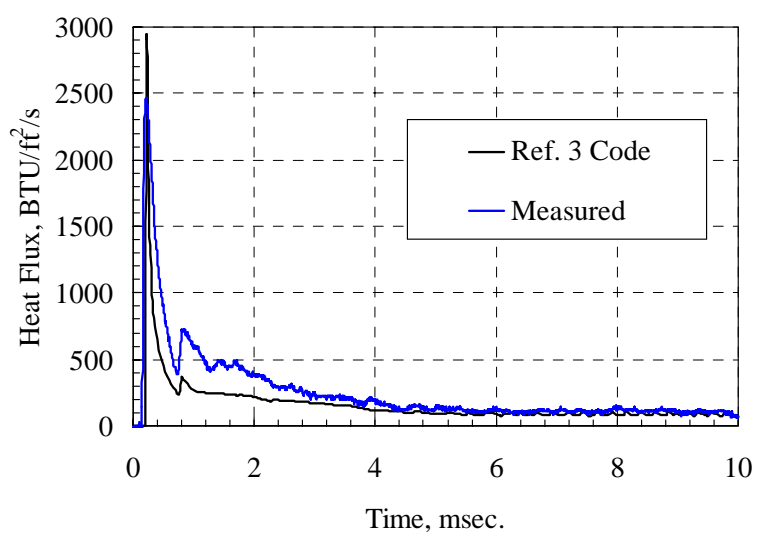

Figure 3.-Computed and measured instantaneous heat flux to the wall of a single-shot detonation tube operating stoichiometrically with $\mathrm{H}_{2}$ /Air. The comparison was made approximately $1.0 \mathrm{in}$. from the exit of a $72.0 \mathrm{in.} \mathrm{tube.}$

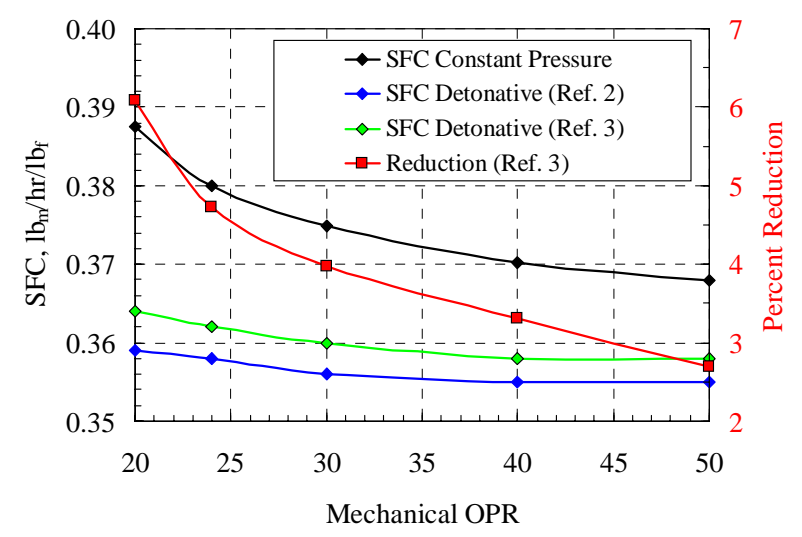

Figure 4.-Specific fuel consumption for constant-pressure, and detonative combustion-topped turbofan engines as a function of mechanical overall pressure ratio. Idealized detonative calculations are based on the work of refs. 2 and 3. Sea-Level static flight conditions are assumed.

\section{Numerical Heat Flux Model}

The heat flux model is implemented as a source term in the governing energy equations. The source term strength depends upon a calculated local heat transfer coefficient and the difference between local gas and wall temperature. The calculated heat transfer coefficient is based on the Reynolds-Colburn analogy between heat transfer coefficient and skin friction coefficient. Thus, it depends on local fluid velocity and density, as well as fluid properties such as Prandlt Number, and viscosity. The skin friction coefficient is calculated using a semi-theoretical correlation obtained from experimental measurements on wave rotors. ${ }^{11}$ It is noted that because the heat transfer model is closely coupled to the viscous loss model (i.e., skin friction), it cannot be applied independently. Hence losses due to friction on the tube walls are included in the analysis which follows.

Figure 3 shows a comparison of computed and measured heat flux several diameters from the exit plane of a stoichiometric $\mathrm{H}_{2} /$ air PDE. The PDE was operated in single shot mode, with air flowing continuously, and the fuel pulsed. The tube walls were initially at ambient temperature of approximately $520 \mathrm{R}$. ${ }^{12}$ The tube was $6 \mathrm{ft}$. long with a diameter of $2.055 \mathrm{in}$. over the first $3 \mathrm{ft}$., transitioning to $2.6 \mathrm{in.}$ over the remaining length. The heat flux gauge was a Vatell Corporation Heat Flux Microsensor, model HFM7EH. The numerical simulation (code) used 200 cells. The single ratio of specific heats used in the code was set to 1.3, the Prandlt Number to 0.7, and the viscosity at $4.46 \times 10^{5} \mathrm{lb} / \mathrm{mt}$-s. It can be seen that computed and measured heat flux are similar in magnitude and form. Thus, it is believed that the model used in the code is of sufficient accuracy for use in the present effort.

\section{Candidate Engine}

For turbojet engines, it can be seen by the idealized results of fig. 1 that with a fixed turbine inlet temperature, the benefit of a detonative pressure-gain combustor (DPGC) increases as mechanical OPR decreases. Figure 4 shows a similar trend for turbofan engines. Here, the same idealized performance curves for the detonative device were used as for fig. 1. Rather than fixing the turbine inlet temperature however, the amount of heat added per pound of air was fixed (i.e., the change in enthalpy across the combustor was fixed). Realistic efficiencies for the turbomachinery components were used, which increases the SFC reduction obtained. An appropriate total pressure drop was used for the baseline conventional combustor (see Appendix 1). Cooling for the high pressure turbine was also accounted for. The addition of a pressure-gain combustor necessitates a booster pump to raise the pressure of the turbine cooling air from the compressor discharge pressure to a pressure slightly above the combustor discharge. The booster must be driven by the turbines and thus represents a loss to the system. The booster stage was modeled in the cycle deck that produced the results of fig. 4. In principle, turbine cooling air could be supplied by a complex detonative cycle having multiple inflow and outflow valves (or ducts if the tubes rotate). The performance of the device suffers however, and this loss is arguably larger than that incurred through the use of a booster pump. 
The more realistic (and relevant) turbofan performance curves of fig. 4 show the same trend as fig. 1. Lower mechanical OPR yields greater benefits from DPGC. Since there are additional, inevitable losses associated with DPGC, it is prudent to choose a candidate engine system that shows the maximum benefit. That is, to choose a low OPR engine. On the other hand, few commercial propulsion systems utilize engines with OPR values below 20. Thus, a 24:1 OPR candidate engine, representative of a typical regional transport turbofan was selected for the present investigation on the impact of thermal loading. The relevant parameters of the baseline engine are listed in table A1.

The mean diameter of the high pressure compressor (HPC) is assumed to be $13.7 \mathrm{in}$. This is the diameter on which the series of tubes assumed to comprise the DPGC will lie. This is shown in fig. 5 . The length of the DPGC is assumed to be $15 \mathrm{in}$. for all of the results to follow. This length was chosen with the understanding that a practical DPGC will almost certainly have associated inlet and exhaust ducting that will likely at least double the total device length. Since adding length to an engine results in an installed performance penalty, it is of paramount importance to minimize the value. A length of $15 \mathrm{in}$. is thus an estimate (albeit unsubstantiated) of the shortest possible tube in which reliable, repetitive detonations may be obtained.

\section{Tube Stress Model and Wall Temperature Limits}

With the particular implementation method chosen (Methods I-IV described in the Introduction), the tube dimensions listed above, and the DPGC inlet and exhaust gas conditions determined by the candidate engine, limit cycles can be computed using the numerical code. Mass flux per tube can then be determined, and hence, required tube diameter and/or tube number can be obtained. For implementation methods I-III, the tubes are conceptually arranged so that they are just touching one another (see fig. 5). For method IV, space is left between the tubes to allow for bypass air. The above procedure is done initially assuming that the tubes are adiabatic, since the wall temperature on which heat transfer calculation are based is, as yet, unknown.

With the tube diameter known, and the limit cycle computed, the cyclic stresses can be estimated. These are predominantly hoop stresses. In the case of rotating tubes, additional stresses must be assessed due to centrifugally induced components. Considerations of high-cycle fatigue, and knowledge of modern super-alloy material properties allows a reasonable estimate of an acceptable wall temperature. These procedures are described below.

\section{A. Stress Estimation}

The hoop stress induced on the inner wall of a uniformly pressurized tube of infinite length can be expressed as ${ }^{13}$

$$
\frac{\sigma_{\text {hoop }}}{p-p_{\text {amb }}}=1+\frac{2}{\left.\left[\delta / r_{i}\right)^{2}+2\left(\delta / r_{i}\right)\right]}
$$

where $p$ is the tube pressure, $p_{a m b}$ is the external pressure (presumed here to be the compressor discharge), $\delta$ is the wall thickness, and $r_{i}$ is the inner radius of the tube. Of course, the tubes of present study are not infinite, nor are the pressures uniform in space or time as eq. (1) assumes. Dynamic analysis may yield period stresses several times larger or smaller than eq. (1). However, in the absence of such analyses, eq. (1) is a reasonable estimate.

In the present investigation a value of $\delta / r_{i}=0.25$ was used. From eq. (1), this yields $\frac{\sigma_{\text {hoop }}}{p-p_{\text {amb }}}=4.56$. This choice is an estimate which balances desirability of lightweight components, and thus small $\delta / r_{i}$ with the need to reduce stress, and thus large $\delta / r_{i}$. In order to illustrate the cyclic nature of the stress, fig. 6 shows a computed time history of the hoop stress at the mid-length of a fully filled, stoichiometrically JP fueled, DPGC tube as a function of time. The inlet conditions correspond to Sea Level Static discharge conditions of a 24:1 compressor. Also shown 


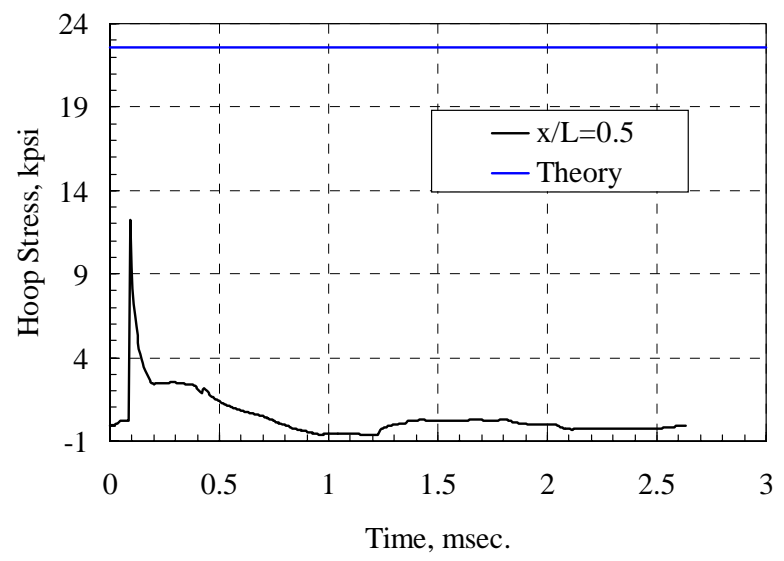

Figure 6.-Computed hoop stress at the mid-length of a fully filled, stoichiometrically JP fueled, DPGC tube as a function of time. The inlet conditions correspond to Sea Level Static discharge conditions of a 24:1 compressor.

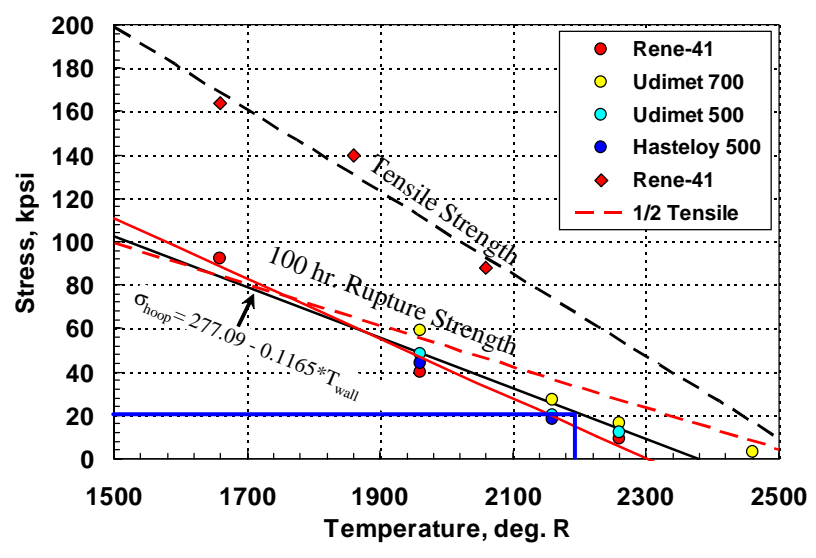

Figure 7.-High temperature strengths of various superalloys.

in the figure is the stress due to the theoretical peak pressure behind the shock of a detonation propagating into a stationary flow with the same heat release as the computed result. ${ }^{14}$ The discrepancy between computed peak and the theoretical value is due to three factors:

1. A relatively crude 200 grid spacing was used in the computation.

2. The detonation in the computed results is propagating into a more realistic, purge-induced Mach 0.3 flow with a corresponding static pressure below the ambient value assumed for the theoretical calculation.

3. The simplicity of the reaction model and the monotonicity requirement inherent in the code cannot capture true shape of a detonation. Peak shock pressures are always truncated.

With regard to performance estimates, the fact that the code truncates this peak is of little consequence. This is because the time duration of the peak is very small. With regard to hoop stress estimates, there is clearly a significant impact. For the present study therefore, the theoretical value is used. Note however that due to the second factor listed above, this is probably somewhat severe.

\section{B. Wall Temperature Limit}

Strength properties of several superalloy materials are shown in fig. 7 as a function of temperature. ${ }^{15}$ Actual fatigue strength data (the stress level at which nearly unlimited cycles can occur) was not available. However, the plot shows ultimate tensile strength for Rene-41, and the $100 \mathrm{hr}$. rupture strength for the other alloys. The $100 \mathrm{hr}$. rupture strength is considered a reasonable estimate for fatigue strength since both are related to creep. Another estimate for fatigue strength states that it is one half of the ultimate tensile strength. ${ }^{16}$ This estimate is also shown on the plot. For the present study, an average of the two estimates was used, and is shown as a solid black line in the figure. The functional formula is:

$$
\sigma_{\text {hoop }}=277-0.1165 T_{\text {wall }}
$$

With the hoop stress estimates known, and eq. (2), the allowable wall temperature for the given DPGC method can now be determined. The process is illustrated graphically in fig. 7. Here the peak theoretical cyclic stress from fig. 6 is plotted as a horizontal blue line. The intersection of this line with that from eq. (2) marks the maximum allowable wall temperature. Note that good engineering practice would dictate operation well below the fatigue limit. Thus, eq. (2) represents a very high allowable wall temperature estimate. 


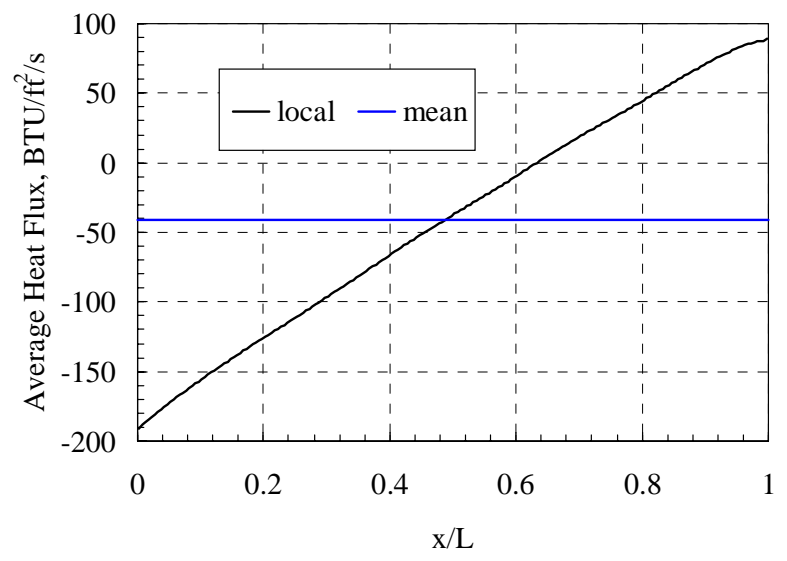

Figure 8. Computed heat flux distribution along a DPGC tube using Method I, lean, fully fueled detonation.

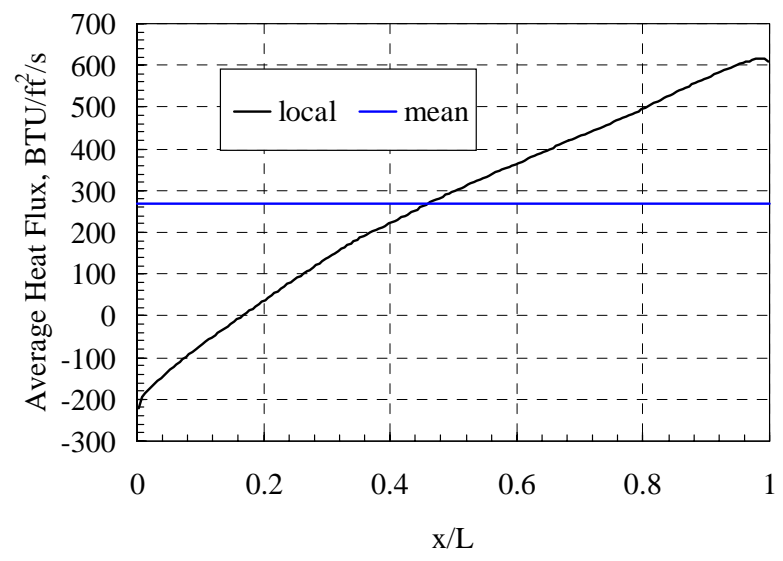

Figure 9. Computed heat flux distribution along a DPGC tube using Method IV, lean, fully fueled detonation.

\section{Thermal Load Assessment}

With the allowable wall temperature established, the simulation code may be used to assess the thermal load imposed on a single tube of the DPGC unit by a given implementation method. More accurately, the code may be used to assess whether the allowable wall temperature can be maintained. The code is rerun with the heat transfer source terms activated. The walls are assumed to be at the allowable wall temperature along the entire length of the tube. When a limit cycle has again been reached, the mass averaged total temperature is then compared to the adiabatic result run earlier. If the temperature is lower, a control volume analysis will show that there must be net heat transferred to the wall. That is, the wall temperature will rise above its allowable value. The implementation method is therefore considered unacceptable. If the temperature is equal to or slightly above the adiabatic value, then the method is acceptable, and the overall pressure ratio is computed.

Note that since this thermal loading criteria assesses only net integrated heat flux along the entire length of the tube, it may be considered a 'bare minimum' methodology. No consideration is made for local heat flux at a point, which may be substantial. For example, a given implementation method may yield large heat flux into the wall at the exhaust end of the tube (leading to excessive temperatures) and large heat flux from the wall at the inlet end. This is likely to be an impractical situation, as it would lead to excessive temperature gradients; however if the sum of the two end heat fluxes is zero, the present criteria will deem it acceptable. This is illustrated in fig. 8 which shows the time averaged distribution of heat flux for the Method I DPGC implementation. The net, or mean heat flux is shown as a horizontal line. It is slightly less than zero indicating a small heat flux from the wall. Thus, it meets the acceptable criteria. The local distribution however indicates substantial variation in heat flux.

\section{A. External Heat Transfer: Method IV}

The load assessment technique just described is applicable for implementation Methods I-III. These methods require all of the core air and fuel to pass through the tubes. Thus, the only surface over which significant heat transfer can take place is that of the tube inner wall. Method IV however, utilizes bypass air passing around the detonation tubes. Presumably, the air passing around the tubes transfers as much heat from the walls as the internal flow transfers to them. This is a substantial amount of heat. Figure 9 shows the computed time-averaged distribution and mean heat flux to the tube walls for the Method IV, stoichiometric, fully fueled, DPGC. Using standard convective heat transfer coefficient correlations found in the literature,${ }^{17}$ it is found that in order to achieve heat flux rates of this magnitude on the outside of the tube (i.e., from the walls into the bypass flow), unreasonable velocities exceeding the local speed of sound are required. Thus, it is clear that surface area augmentation, such as fins will be necessary. Analysis of this sort of geometry is beyond the scope of the present effort. Thus, it is simply assumed in the present study that an external convection scheme can be found that will remove the required amount of heat. However, the performance impact of this scheme can be partially assessed. Any sort of surface augmentation will result in a loss of available total pressure to the bypass flow. It is not unreasonable to estimate that this will be at least as large as that which occurs in a conventional steady combustor with air used to cool the liner. Typical values are near 5 percent. Thus, for the present study, a total pressure loss of 5 percent is imposed on the bypass flow. 
Furthermore, as the bypass flow draws heat away from the tube walls, it must necessarily get hotter (correspondingly, the flow inside the tubes is cooled by the walls). The bypass and tube flows are then conceptually mixed downstream of the DPGC; however, the useful work that can be exchanged between the flows has been reduced due to the prior heat exchange. This is reflected in the mixing model, which is written as

$$
\begin{aligned}
\frac{\overline{\dot{m}}_{\text {bypass }}}{\overline{\dot{m}}_{\text {DPGC }}}\left(\left[\frac{P R_{\text {mix }}}{P R_{\text {bypass }}}\right]^{\frac{(\gamma-1)}{\eta}}-1\right)= \\
\frac{T R_{\text {DPGC }}}{T R_{\text {bypass }}}\left(1-\left[\frac{P R_{\text {mix }}}{P R_{D P G C}}\right]^{\frac{\eta(\gamma-1)}{\gamma}}\right)
\end{aligned}
$$

Here, $T R$ is a mass-averaged total temperature ratio across a given section, $P R$ is a total pressure ratio across a given section, $\overline{\dot{m}}$ is a time-average mass flow rate, and $\eta$ is an efficiency. This is a transcendental equation which can be solved for $P R_{\text {mix }}$ to find the mixed total pressure available to the downstream turbine. Although not obvious, solution of eq. (3) results in a lower mixed total pressure if either $T R_{\text {bypass }}$ rises (heat transferred to the bypass flow) or $T R_{D P G C}$ falls. This effect, combined with the imposed bypass total pressure loss, accounts for the performance impact of bypass cooling using the Method IV implementation.

Equation 3 is a mixing calculation which balances the enthalpy extracted from the DPGC flow with that transferred to the bypass flow. The enthalpy transfer is assumed to proceed with a given efficiency, $\eta$. The value for this efficiency is not obvious. However, eq. (3) can be applied to ejector-based, thrust producing systems ${ }^{18}$ if the thrust is assumed to arise from expanding the flow from the mixed total pressure. Therefore, if experimental ejector data is available, including thrust augmentation values, entrainment rates, and flow enthalpies, an efficiency can be obtained. This was the approach used in the present work. Data was obtained from an unsteady, pulsejet-driven ejector experiment which exhibited very high thrust augmentation levels. ${ }^{18}$ Thus, the efficiency values obtained represent a relatively high (that is optimistic) estimate. That value was found to be $\eta=0.5$.

\section{Results}

The four implementations were run in the code subject to the thermal loading criteria discussed above. The results are summarized in table 1 . The columns of the table are self-explanatory with two exceptions:

- The column labeled $P R_{\text {ideal }}$ represents the computed total pressure ratio obtained without heat transfer (or viscous) effects modeled, at the target temperature ratio.

- The darkened row corresponding to Method II indicates that the method failed to meet the cooling criteria. This is evident by the fact that the computed temperature ratio is below the target value of 1.91. This, in turn indicates that net heat was transferred to the walls.

Most of the methods were found to successfully meet the zero net-heat flux criteria. Their relative impact on engine performance enhancement varied. This is illustrated in fig. 10 which shows the reduction in SFC from the baseline 24:1 OPR engine for the various methods and for refs. 2 and 3 idealized calculations. The reductions are plotted as a function of the computed pressure ratios. Method II, shown in blue failed to meet the criteria, and hence is discounted from consideration. Furthermore, because it resulted in an exit temperature below the target value, its subsequent use in the engine cycle can no longer be directly compared to the baseline engine. The successful thermal management methods illustrate a general trend whereby the benefit in terms of SFC reduction rises rapidly from the baseline pressure ratio of 0.985 , but flattens substantially as the pressure ratio increases. The thermodynamic reasons for this non-linear behavior are not clear as of this writing; however, it has been observed that the degree of non-linearity is dependant on the turbomachinery component efficiencies, and the prescribed turbine inlet temperature. It is also slightly affected by the boost pump cooling scheme employed, since this penalty becomes more pronounced as the DPGC pressure ratio rises. 
Table 1.-Summary results from thermal load, and performance analysis using four DPGC implementation methods on a baseline 24:1 OPR turbofan engine operating at sea level conditions.

\begin{tabular}{|c|c|c|c|c|c|c|c|c|c|c|}
\hline \multirow[t]{2}{*}{ Method } & \multirow[t]{2}{*}{$\mathrm{TR}^{* *}$} & \multirow{2}{*}{\multicolumn{2}{|c|}{ PR }} & \multirow{2}{*}{\multicolumn{2}{|c|}{$\mathrm{PR}_{\text {ideal }}$}} & \multirow[t]{2}{*}{$\begin{array}{l}\text { Tube } \\
\text { Count }\end{array}$} & $\begin{array}{l}\text { Tube Firing } \\
\text { Frequency }\end{array}$ & $\mathrm{T}_{\text {wall }}$ & $\begin{array}{c}\text { Tube } \\
\text { Diameter }\end{array}$ & $\begin{array}{c}\text { Engine }^{+} \\
\text {SFC }\end{array}$ \\
\hline & & & & & & & (Hz.) & (deg. R) & (in.) & $1 b_{m} / h r-1 b_{f}$ \\
\hline I & 1.921 & \multicolumn{2}{|c|}{1.114} & \multicolumn{2}{|c|}{1.139} & 37 & 270 & 2300 & 0.927 & 0.3685 \\
\hline II & 1.856 & \multicolumn{2}{|c|}{1.203} & \multicolumn{2}{|c|}{1.239} & 31 & 223 & 2182 & 1.122 & 0.3550 \\
\hline III & 1.908 & \multicolumn{2}{|c|}{1.163} & \multicolumn{2}{|c|}{1.222} & 36 & 122 & 2182 & 0.95 & 0.3648 \\
\hline \multirow[t]{2}{*}{ IV } & \multirow[t]{2}{*}{1.909} & DPGC $^{*}$ & $\operatorname{mix}$ & DPGC $^{*}$ & $\operatorname{mix}$ & \multirow{2}{*}{8} & \multirow{2}{*}{379} & \multirow{2}{*}{2182} & \multirow{2}{*}{1.050} & \multirow{2}{*}{0.3717} \\
\hline & & 1.429 & 1.072 & 1.481 & 1.134 & & & & & \\
\hline
\end{tabular}

* Method IV results show the pressure ratio of the DPGC device and the pressure ratio after mixing with the bypass flow according to eq. 3. For the ideal case no total pressure loss or heat transfer to the bypass flow is incurred.

${ }^{* *}$ Baseline or target $\mathrm{TR}=1.91$.

${ }^{+}$Baseline SFC $=0.3800 \mathrm{lb} / \mathrm{hr}-\mathrm{lb}_{\mathrm{f}}$

At first glance, fig. 10 seems to show a relatively small performance reduction due to thermal management. However, the ideal SFC reduction obtained from ref. 3 was 4.72 percent. That obtained using Method IV was 2.17 percent. Thus, thermal management alone can cost nearly a half of the potential benefit. Furthermore, this penalty is just one of many penalties that will inevitably arise from practical DPGC implementation. Thus, the impact is clearly a concern.

Nevertheless, the results presented are encouraging as they indicate that, from a preliminary point of view, the thermal loads on the DPGC device can be managed, and that significant performance enhancement is still possible. It should be kept in mind however that the adequacy requirements were relatively generous as no tube wall temperature gradients were considered, and no safety factor for allowable stress was employed.

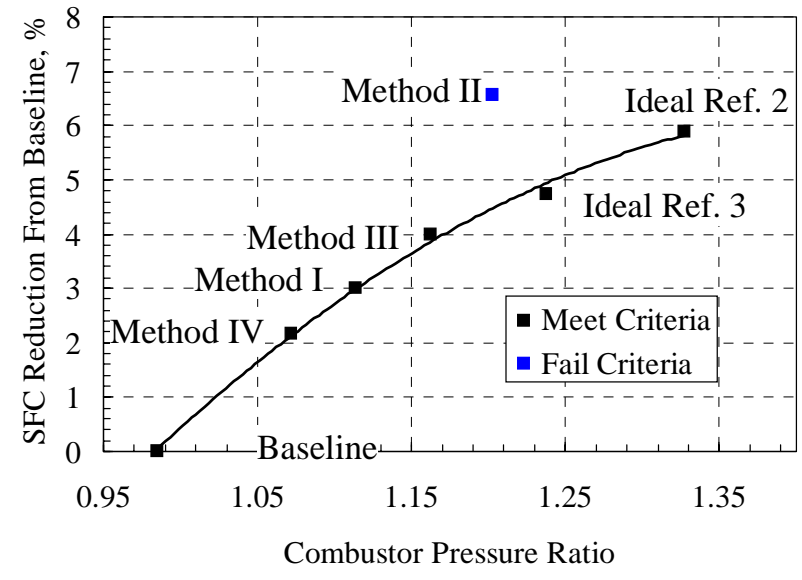

Figure 10.-Percent reduction in SFC from the baseline 24:1 OPR engine for the various DPGC implementation methods methods and for ref. 2 and 3 idealized calculations as a function of computed overall pressure ratio.

\section{Discussion}

Although the focus of the present paper is on thermal management issues, it is worthwhile to briefly consider the results in light of some other, obvious implementation considerations.

The Method I cooling scheme, while successful, requires detonation of exceptionally lean mixtures. The wellknown difficulties associated with lean detonation, despite the high DPGC inlet pressures and temperatures in the gas turbine environment, are likely to make this implementation method very challenging.

The Method III scheme is also successful. However, because all of the core flow is passing through the tubes, and much of this flow is relatively cool, the flow emitted from the exhaust end of the tubes will be highly stratified. Presenting such a stratified flow to the downstream turbine is likely to result in substantial performance and/or structural penalties. Thus, it must be mixed. The mixing process will produce its own penalties (e.g., added length and weight) and these must be evaluated before this method can be considered viable.

Method IV is intuitively attractive since it is the most like a conventional combustor concept, and efficient mixing techniques for bypass flow are established. Furthermore, unlike the other three methods, which rely on heat transfer to and from only the inner surface of the tubes, this method uses both the inner and outer surfaces. This may make it amenable to thermal barrier coatings. However, it produces the lowest performance enhancement, and the enhancement results from using a somewhat 'generous' efficiency in the mixing calculation. Furthermore, it is not known whether the bypass flow can, in fact, draw the substantial heat load from the tubes. 


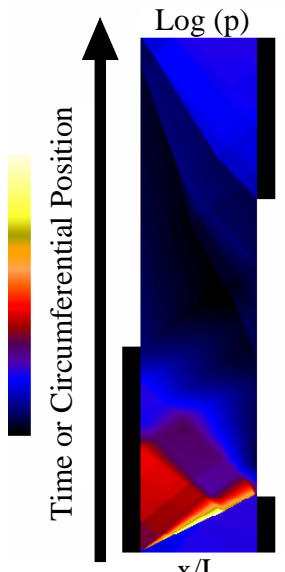

$\mathrm{x} / \mathrm{L}$

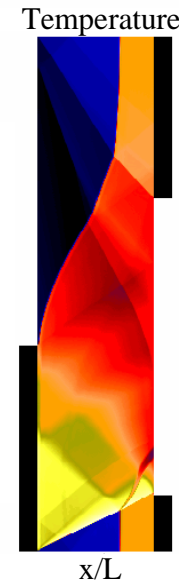

$\mathrm{x} / \mathrm{L}$

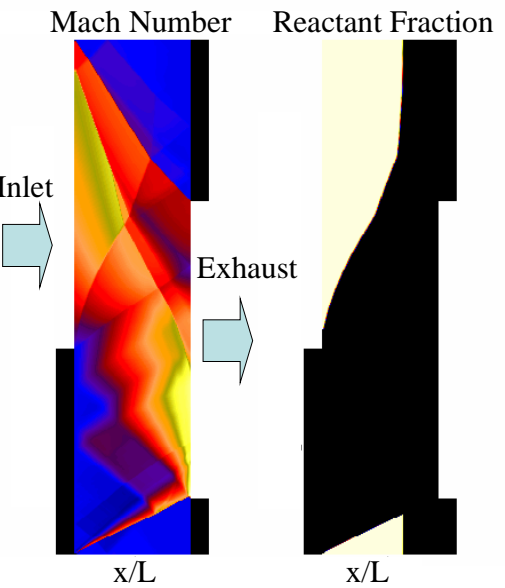

Figure 11.-Contours of pressure, density, Mach number, and reactant fraction for one cycle of an idealized, detonative wave rotor cycle using Method I.

\section{A. Spinning the Tubes}

As mentioned in the introduction, only limited consideration will be placed on this approach. This is not because the approach lacks merit, but because time constraints simply did not allow substantial investigation for this study. A much more thorough investigation is warranted based on its numerous potential advantages.

One possible implementation of spinning tubes would envision fixing the rotary valve of fig. 5 , and rotating the bank of tubes. The open valve segments would then be equipped with entry ducts. In principle, all of the Methods IIV could be examined, along with their associated wave cycles. However, while there may be practical reasons for doing this (e.g., vastly simplified fuel distribution), ${ }^{10}$ there is no reason to expect that the performance or cooling results would change. It may be argued that a slight increase in the bypass cooling potential of Method IV would result from the rotational component of the tubes, but this would likely be offset by additional total pressure losses. Furthermore, spinning the tubes may result in substantial centrifugally induced stresses. At some points, these stresses may coincide with the hoop stresses, and thus compound them. Thus, cooler walls would be required, and performance would suffer. From this rationale, the concept of Methods I-IV implemented with rotating tubes seems of little value.

\section{The Wave Rotor Approach}

If, in addition to spinning the tubes, a valve is added to the exhaust end of the bank of tubes, additional performance potential may exist. Idealized calculations of such cycles indicate that significant performance enhancement may be obtained compared to cycles where the exhaust is open. ${ }^{10,19}$ An example of such a cycle is shown in fig. 11. Here, contour plots of pressure, temperature, Mach number and reactant fraction are shown over the course of one cycle, along the length of the tube. Walls are shown at the ends of each contour as black rectangles. The cycle was computed using the Method I, lean detonation. The temperature ratio is 1.916, and the pressure ratio is 1.373 . This is nearly identical to the idealized results derived from ref. 2 , and substantially higher than those from ref. 3.

Only the Method I, lean detonation approach was examined in a wave rotor configuration. The same allowable wall temperature of $2300 \mathrm{R}$ was used as in the stationary tube analysis. In light of the previous comments made regarding additional rotational stresses, this is probably a high value. In fact, it was found that the Method I wave rotor approach failed to meet the zero net heat flux criteria, though barely. The computed temperature ratio was 1.892. This is very close to, but less than the target value of 1.91 . The overall pressure ratio was 1.13 , slightly higher than the stationary, open tube case. The tube diameter required to pass the core flow was found to be 0.627 in. This is substantially smaller than the stationary tubes and partially accounts for the overall pressure ratio being substantially lower than the ideal value of 1.373 .

From the perspective of the very limited examination done in this paper, wave rotor configurations appear to offer no substantial benefits over stationary tubes for detonative pressure-gain combustors. However, the wave rotor approach needs a much more thorough investigation before any conclusions may be drawn. Implementation methods II-IV need to be examined in this configuration, as do other detonative wave cycles beyond that shown in fig. 11. ${ }^{19}$ The impact of rotational stresses needs adequate assessment as well. 


\section{Conclusion}

The pulse detonation engine concept was examined in a turbomachinery-based hybrid cycle arrangement in which the device was acting as a detonative pressure-gain combustor (DPGC). The objectives of the examination were twofold. The first was to quantify the performance enhancement that could ideally be achieved compared to constant pressure combustion. The second was to conduct a preliminary assessment of the device thermal management requirements and their impact on performance. Four cooling methods were examined in a multiplestationary tube arrangement, and one method was examined in a rotary tube arrangement. Three of the methods considered only internal convective cooling, while the fourth considered external cooling using bypass flow. For all of the methods, a validated one-dimensional, unsteady numerical code was utilized which contained a reasonably accurate heat transfer model. It was found that ideal DPGC devices topping gas turbine engines with realistic component efficiencies and mechanical compression ratios can reduce specific fuel consumption between 3 and 6 percent over constant pressure combustors. The imposed heat loads were found to be large but potentially manageable with a variety of cooling schemes; however, the performance penalties were often substantial. Up to half of the ideal SFC benefit was lost. Thus, it is concluded that successful DPGC thermal management schemes are a formidable challenge and represent a key enabling technology for the viability of the concept.

\section{References}

${ }^{1}$ Oates, Gordon, C., Aerothermodynamics of Gas Turbine and Rocket Propulsion, American Institute of Aeronautics and Astronautics, 1997, Chapter 5.

${ }^{2}$ Heiser, W.H and Pratt, D.T. "Thermodynamic Cycle Analysis of Pulse Detonation Engines," AIAA Journal of Propulsion and Power, vol. 18, no. 1, 2002, pp. 68-76.

${ }^{3}$ Paxson, D.E., "A Performance Map for Ideal Air-Breathing Pulse Detonation Engines," AIAA paper 20013465, July, 2001, also, AIAA Journal of Propulsion and Power, pending.

${ }^{4}$ Heiser, W., and Pratt, D. "Comment on "Analytical Model for the Impulse of a Single-Cycle Pulse Detonation Tube," AIAA Journal of Propulsion and Power, vol. 20, no. 1, 2004, pp. 189-191.

${ }^{5}$ Petters, D.E., and Felder, J.L., "Engine System Performance of Pulse Detonation Concepts Using the NPSS Program," AIAA-2002-3910, July, 2002.

${ }^{6}$ Kelly, J., “After Combustion: Detonation,” Popular Science, September, 2003.

${ }^{7}$ Kandebo, S., "Taking the Pulse," Aviation Week \& Space Technology, March, 8, 2004.

${ }^{8}$ Paxson, D.E., "Optimal Area Profiles for Ideal Single Nozzle Air-Breathing Pulse Detonation Engines," AIAA2003-4512, July, 2003.

${ }^{9}$ Welch, G.E., "Wave Engine Topping Cycle Assessment," AIAA-97-0707, January, 1997.

${ }^{10}$ Nalim, R.M., and Paxson, D.E., "A Numerical Investigation of Premixed Combustion in Wave Rotors," ASME Journal of Engineering for Gas Turbines and Power, vol. 119, no. 3, 1997, pp. 668-675, also ASME Paper 96-GT116, June, 1996, also, NASA TM 107242.

${ }^{11}$ Paxson, D.E., Wilson, J., "Recent Improvements to and Validation of the One Dimensional NASA Wave Rotor Model," NASA TM 106913, May, 1995.

${ }^{12}$ Wilson, J., Breisacher, K., Unpublished test results using the NASA Glenn 2 Inch Diameter PDE, 2001, also see Thomas, S. Deloof, R., Dougherty, K., "A Review of the NASA Glenn Research Center Pulse Detonation Engine Technology (PDET) Project," presented at 14th Annual Symposium on Propulsion, University Park, PA, December 10-11, 2002.

${ }^{13}$ Timoshenko, S.P., Theory of Elasticity, McGraw-Hill Book Company, New York, 1970. pp. 71.

${ }^{14}$ Thompson, P.A., Compressible Fluid Dynamics, Rensselaer Polytechnic Institute, 1988, Chapter 7.

${ }^{15}$ Casamassa, J.V., and Bent, R.D., Jet Aircraft Power Systems, McGraw-Hill, 1965, pp. 377.

${ }^{16}$ Shigley, J., Mitchell, L., Mechanical Engineering Design, McGraw-Hill Book Company, New York, 1983, Chapter 7.

${ }^{17}$ Kayes, W. M., and Crawford, M. E., Convective Heat and Mass Transfer, McGraw-Hill Book Company, New York, 1980, Chapter 12.

${ }^{18}$ Paxson, D.E., Wilson, J., and Dougherty, K.T., "Unsteady Ejector Performance: An Experimental Investigation Using a Pulsejet Driver," AIAA paper 2002-3915, July, 2002.

${ }^{19}$ Snyder, P.H., Alparslan, B., Nalim, M.R., "Gas Dynamic Analysis of the CVC, A Novel Detonation Cycle," AIAA paper 2002-4069, July, 2002.

${ }^{20}$ Mattingly, Jack D., Elements of Gas Turbine Propulsion, McGraw-Hill, 1996. 


\section{Appendix 1-Non-Ideal Cycle Analysis}

In order to assess the impact of detonation tube thermal management schemes on the overall system performance, it was necessary to perform full-engine cycle analysis for each case. While high-fidelity cycle simulation tools are available, such as the governmentindustry standard NPSS code, ${ }^{7}$ a less complex conceptual design cycle analysis code, based on the methods described in ref. 20, was selected for this study. The relatively simple nature of the analysis code allowed for rapid setup of various combustor/engine configurations, allowing more configurations to be examined in a short time period. This simplified cycle analysis code, while somewhat compromising absolute accuracy, provides correct insight into relative performance trends and the magnitude of the impacts on engine performance of various design choices.

The conceptual design code is set up to analyze separate flow turbofans using different ratios of specific heats in the compression system (1.385) versus the combustion and turbine systems (1.33). Polytropic efficiencies are used for all turbomachinery components in place of detailed performance maps. Cooling flows, engine bleed, and power take-off are all modeled. Both ondesign and off-design analysis are available. Inlet, nozzle, and mixing losses are modeled as simple total pressure losses using typical values from current production engines. Power losses due to bearings and seals are also estimated using typical values. This code was validated against a number of textbook examples and detailed engine simulations available in-house at NASA Glenn Research Center. Errors in uninstalled SFC were typically on the order of 5 percent, but were consistent across various flight conditions, giving accurate overall trends.

Figure A1 shows a block diagram of the configuration of the DPGC engine with an auxiliary cooling air boost compressor. Adjustments to the configuration were made for each case as needed. Table 1 gives the cycle design parameters used throughout the study, as well as all of the required component efficiencies. The combustor pressure ratio was modeled as previously described for each case.

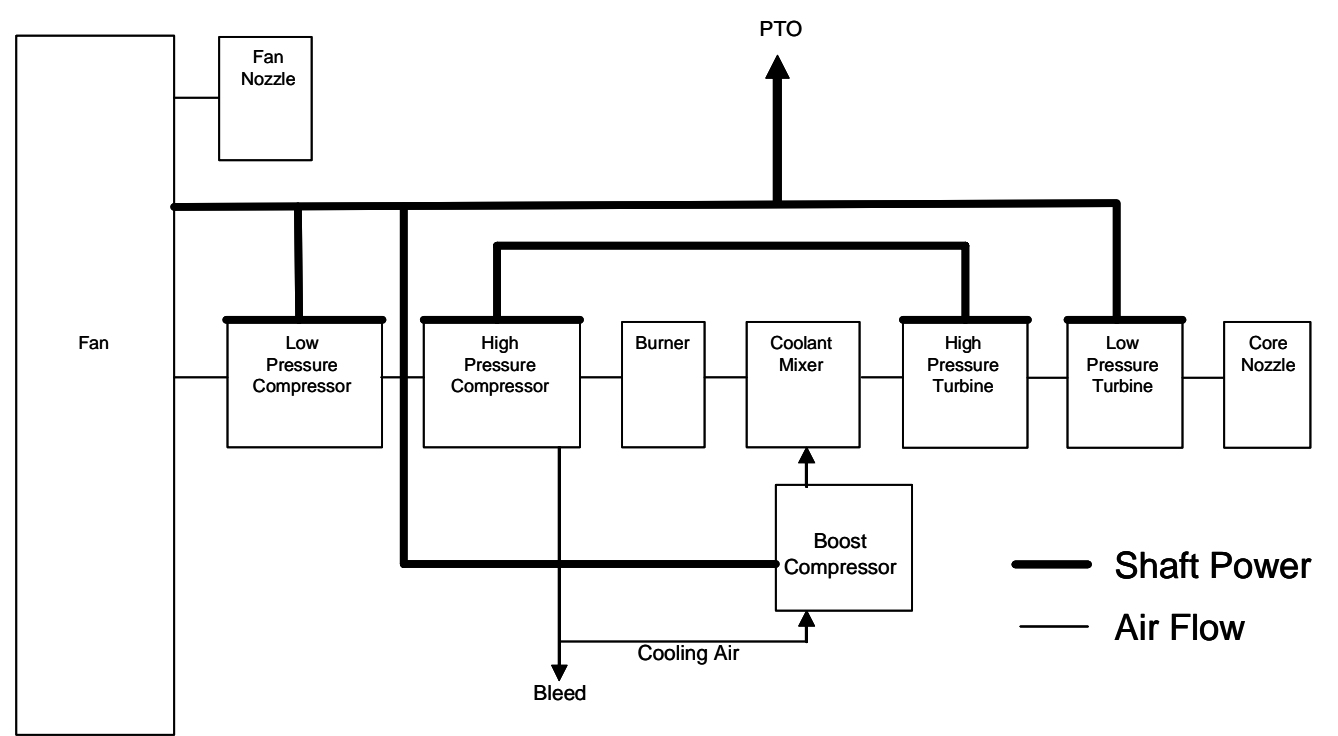

Figure A1.—Engine layout for cycle analysis. 
Public reporting burden for this collection of information is estimated to average 1 hour per response, including the time for reviewing instructions, searching existing data sources, gathering and maintaining the data needed, and completing and reviewing the collection of information. Send comments regarding this burden estimate or any other aspect of this collection of information, including suggestions for reducing this burden, to Washington Headquarters Services, Directorate for Information Operations and Reports, 1215 Jefferson Davis Highway, Suite 1204, Arlington, VA 22202-4302, and to the Office of Management and Budget, Paperwork Reduction Project (0704-0188), Washington, DC 20503.

\begin{tabular}{|l|l|l|}
\hline 1. AGENCY USE ONLY (Leave blank) & $\begin{array}{c}\text { 2. REPORT DATE } \\
\text { August } 2004\end{array}$ & $\begin{array}{c}\text { 3. REPORT TYPE AND DATES COVERED } \\
\text { Technical Memorandum }\end{array}$ \\
\hline
\end{tabular}

4. TITLE AND SUBTITLE 5. FUNDING NUMBERS

Thermal Load Considerations for Detonative Combustion-Based Gas Turbine Engines

6. AUTHOR(S)

WBS-22-708-90-05

Daniel E. Paxson and H. Douglas Perkins

7. PERFORMING ORGANIZATION NAME(S) AND ADDRESS(ES)

National Aeronautics and Space Administration

John H. Glenn Research Center at Lewis Field

Cleveland, Ohio 44135-3191

8. PERFORMING ORGANIZATION REPORT NUMBER

E-14689

9. SPONSORING/MONITORING AGENCY NAME(S) AND ADDRESS(ES)

National Aeronautics and Space Administration

Washington, DC 20546-0001

10. SPONSORING/MONITORING AGENCY REPORT NUMBER

NASA TM-2004-213190

AIAA-2004-3396

\section{SUPPLEMENTARY NOTES}

Prepared for the 40th Joint Propulsion Conference and Exhibit cosponsored by AIAA, ASME, SAE, and ASEE, Fort Lauderdale, Florida, July 11-14, 2004. Responsible person, Daniel E. Paxson, organization code 5530, 216-433-8334.

12a. DISTRIBUTION/AVAILABILITY STATEMENT 12b. DISTRIBUTION CODE

Unclassified - Unlimited

Subject Category: 07

Distribution: Nonstandard

Available electronically at http://gltrs.grc.nasa.gov

This publication is available from the NASA Center for AeroSpace Information, 301-621-0390.

13. ABSTRACT (Maximum 200 words)

An analysis was conducted to assess methods for, and performance implications of, cooling the passages (tubes) of a pulse detonation-based combustor conceptually installed in the core of a gas turbine engine typical of regional aircraft. Temperature-limited material stress criteria were developed from common-sense engineering practice, and available material properties. Validated, one-dimensional, numerical simulations were then used to explore a variety of cooling methods and establish whether or not they met the established criteria. Simulation output data from successful schemes were averaged and used in a cycle-deck engine simulation in order to assess the impact of the cooling method on overall performance. Results were compared to both a baseline engine equipped with a constant-pressure combustor and to one equipped with an idealized detonative combustor. Major findings indicate that thermal loads in these devices are large, but potentially manageable. However, the impact on performance can be substantial. Nearly one half of the ideally possible specific fuel consumption (SFC) reduction is lost due to cooling of the tubes. Details of the analysis are described, limitations are presented, and implications are discussed.

14. SUBJECT TERMS

Pulse detonation engines

17. SECURITY CLASSIFICATION OF REPORT

Unclassified
18. SECURITY CLASSIFICATION OF THIS PAGE

Unclassified
19. SECURITY CLASSIFICATION OF ABSTRACT

Unclassified
15. NUMBER OF PAGES

18

16. PRICE CODE

\section{LIMITATION OF ABSTRACT}

Standard Form 298 (Rev. 2-89) 

